\title{
Skin-protective effects of a zinc oxide- functionalized textile and its relevance for atopic dermatitis
}

This article was published in the following Dove Press journal:

Clinical, Cosmetic and Investigational Dermatology

3 May 2013

Number of times this article has been viewed

\author{
Cornelia Wiegand' \\ Uta-Christina Hipler' \\ Sebastian Boldt ${ }^{2}$ \\ Joachim Strehle ${ }^{2}$ \\ Uwe Wollina ${ }^{2}$ \\ 'Department of Dermatology, \\ University Medical Center Jena, \\ Jena, Germany; ${ }^{2}$ Department of \\ Dermatology and Allergology, \\ Academic Teaching Hospital Dresden- \\ Friedrichstadt, Dresden, Germany
}

Correspondence: Uwe Wollina Department of Dermatology and Allergology, Academic Teaching Hospital Dresden-Friedrichstadt, Friedrichstrasse 4I, Dresden 01067, Germany

Tel +49 35I 480 I685

Fax +4935I 480 1219

Email wollina-uw@khdf.de

\begin{abstract}
Atopic dermatitis (AD) is a chronic inflammatory disease characterized by the impairment of the skin-barrier function, increased oxidative cellular stress, and bacterial colonization. Hence, medical therapies of AD aim to control infection, reduce inflammation, and restore skin-barrier function by use of topical and systemic antibacterial drugs, topical corticosteroids, topical calcineurin inhibitors, and moisturizers. Textiles have the longest and most intense contact with the human skin, and functional textiles with intrinsic properties such as antioxidative capacity and antibacterial activity have been gaining in importance in medical applications. Specially designed textiles may support AD treatment and improve quality of life of AD. Here, we investigated the role of $\mathrm{ZnO}$-functionalized textile fibers in the control of oxidative stress in $\mathrm{AD}$ in vitro and in vivo. In addition, the antibacterial effect and biocompatibility of the $\mathrm{Zn}$ textile was evaluated in vitro. We observed a rapid improvement of AD severity, pruritus, and subjective sleep quality when $\mathrm{AD}$ patients wore the $\mathrm{ZnO}$ textiles overnight on 3 consecutive days. This is possibly due to the high antioxidative capacity of the $\mathrm{ZnO}$ textile, as well as the allocation of strong antibacterial activity. Moreover, it was shown that the $\mathrm{ZnO}$ textiles possess very good biocompatibility and were well tolerated by AD patients.
\end{abstract}

Keywords: atopic dermatitis, antibacterial activity, biocompatibility, functionalized textiles, oxidative stress

\section{Introduction}

The skin is the external barrier of the human body. It is the most versatile human organ, plays a key role in protecting the body against environmental influences, and participates in the regulation of homeostasis and metabolic processes as well as immunological reactions. Exposure to ultraviolet light induces the generation of free radicals in the cells, like reactive oxygen species (ROS) and reactive nitrogen species (RNS). Increased oxidative stress has been documented in affected skin of individuals suffering from atopic dermatitis $(\mathrm{AD})^{1-4}$ and seems to be involved in inflammation, skin-barrier impairment, and itch. Moreover, measurements of transepidermal water loss and corneometry have shown an inverse relation to AD severity. ${ }^{5}$ In addition, patients with AD display an augmented susceptibility to cutaneous bacterial, fungal, and viral infections. ${ }^{6,7}$ Microbial flora of atopic skin exhibits noticeable differences in contrast to normal skin, eg, more than $90 \%$ of patients with $\mathrm{AD}$ are colonized with Staphylococcus aureus, whereas it is found in less than $10 \%$ in healthy individuals. ${ }^{8}$ The carriage rate of AD patients for $S$. aureus was observed to be $>90 \%$ in inflammatory lesions and approximately $76 \%$ in uninvolved skin. ${ }^{9}$ Furthermore, the quantity of S. aureus could be related to the severity of AD., ${ }^{9,10}$ Hence, medical therapies of AD 
aim to control infection, reduce inflammation, and restore skin-barrier function by the use of topical and systemic antibacterial drugs, ${ }^{11}$ topical corticosteroids, topical calcineurin inhibitors, and moisturizers. ${ }^{12-14}$ Textiles have the longest contact with the human skin and have a major impact on its microenvironment. Hence, specially designed textiles may support medical treatment and improve quality of life of patients with AD. ${ }^{15}$

Here, we investigated the role of $\mathrm{ZnO}$-functionalized textile fibers in the control of oxidative stress in AD in vitro and in vivo. In addition, the antibacterial effect and biocompatibility of the $\mathrm{Zn}$ textile was evaluated in vitro.

\section{Material and methods In vivo pilot trial}

We investigated the in vivo effects of a special AD textile, Benevit Zink+ (Benevit Van Clewe, Dingden, Germany), which consists of 74\% Lyocell fiber, 19\% SmartCell sensitive fiber, and 7\% spandex. In this uncontrolled pilot trial, adult patients with moderate to severe AD were enrolled after informed consent. Three days after individualized topical treatment with corticosteroids, calcineurin inhibitors, or coal tar, the $\mathrm{ZnO}$ textile was used for overnight underclothes with trousers and long-sleeve shirts (Figure 1) for three subsequent nights. AD diagnosis was performed according to the clinical criteria of Hanifin and Rajka. ${ }^{16}$ Severity was calculated by the three item severity score index before and after use of the $\mathrm{Zn}$ textile. ${ }^{17}$ The severity of pruritus was scored by the $5 \mathrm{D}$ itch scale. ${ }^{18}$ Subjective quality of sleep was assessed by a modified sleep-habits questionnaire. ${ }^{19}$

\section{In vitro study}

\section{Measurement of antioxidative capacity}

The antioxidative capacity (AOC) of the $\mathrm{ZnO}$ textile against ROS was assessed by an Abel antioxidant test kit with Pholasin for superoxide and other free radicals (Knight Scientific, Plymouth, UK) and scavenging of RNS was determined by Abel antioxidant test kits specific for peroxynitrite anion (Knight Scientific). The assays were performed as described earlier. ${ }^{20}$ In brief, to each $\mathrm{ZnO}$ textile sample $\left(0.25 \mathrm{~cm}^{2}\right.$ and $\left.0.5 \mathrm{~cm}^{2}\right)$ the assay solutions were added. Subsequent to injecting the solution, generating free radicals, luminescence intensity was measured using the Novostar Galaxy plate reader (BMG Labtech, Ortenberg, Germany). A control without sample was included for each assay. Antioxidant activity impedes the development of the luminescence peak (peroxynitrite assay) and decreases its

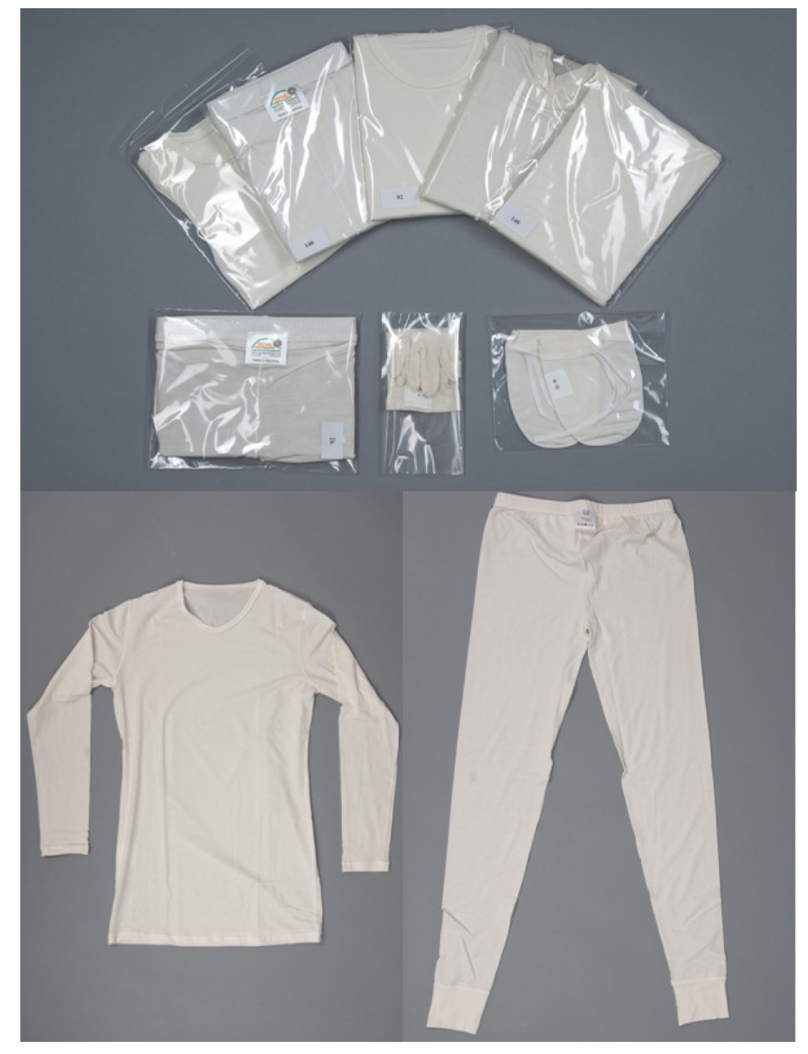

Figure I Benevit Zink+ clothing contains 74\% Lyocell fiber, 19\% SmartCell sensitive fiber (comprised of $\mathrm{ZnO}$ ), and $7 \%$ spandex.

Notes: Adult patients with moderate to severe atopic dermatitis were enrolled after informed consent. This $\mathrm{ZnO}$ textile was used for overnight underclothes in the form of trousers and long-sleeve shirts.

light intensity (peroxynitrite assay and superoxide assay). AOC of a sample was calculated as percentage reduction of peak luminescence, as given in equation (1). All experiments were carried out twice with a triplicate sample set. Results are expressed as means \pm standard deviation. For statistical analysis, Student's $t$-test was performed. Statistical significance was defined as $P<0.05$. Statistically significant results are identified by asterisk symbols: $* * * P \leq 0.001$, $* * P \leq 0.01$, and $* P \leq 0.05$.

$\%$ inhibition $=\frac{[(\text { Peak-control })-(\text { Peak-probe })]}{(\text { Peak control })} \times 100$.

\section{Determination of antibacterial activity according to JIS L 1902}

Testing for antibacterial activity was carried out in accordance with Japanese Industrial Standards L 1902: 2002, as reported previously. ${ }^{21}$ Staphylococcus aureus (American Type Culture Collection 6538) and Klebsiella pneumoniae were obtained from Deutsche Sammlung von Mikroorganismen und Zellkulturen 
(Braunschweig, Germany). For bacteria cultivation, special peptone and Lab-Lemco powder for fabrication of casobouillon and bacteriological agar were purchased from Thermo Fisher Scientific (Waltham, MA, USA). Columbia agar plates with 5\% sheep blood were acquired from BioMeriéux (Marcy l'Etoile, France) and $0.9 \% \mathrm{NaCl}$ solution from Fresenius Kabi (Bad Homburg, Germany). Test microbes were cultivated in caso-bouillon for 24 hours at $37^{\circ} \mathrm{C}$ under aerobic conditions. For experiments, $400 \mathrm{mg}$ samples of the $\mathrm{ZnO}$ textile were inoculated with $200 \mu \mathrm{L}$ test microbe solution and incubated for 24 hours at $37^{\circ} \mathrm{C}$ under aerobic conditions. Polyester material (ITS Textilhandels, Rutzenham, Austria) was used as growth control. For determination of the germ number, the incubated samples were extracted in $0.9 \% \mathrm{NaCl}$ solution supplemented with $0.2 \%$ Tween 20 . Serial dilutions were plated onto Columbia agar plates and incubated for 24 hours at $37^{\circ} \mathrm{C}$. Subsequently, colonies were counted, total colonyforming units (cfu) determined, and growth reduction calculated according to equation (2). A logarithmic microbial growth reduction of less than 0.5 represented no antibacterial activity. Values between 0.5 and 1 were rated as slight, values greater than 1 and less or equal to 3 as significant, and a log reduction greater than 3 as strong antibacterial activity.

Log growth reduction $_{(24 \text { hours })}$ $=$ Log cfu (negative control) - Log cfu (sample) ${ }_{(24 \text { hours })}$.

\section{Evaluation of biocompatibility according to DIN EN ISO I0993-5}

For evaluation of biocompatibility, extracts of the $\mathrm{ZnO}$ textile were fabricated according to the standard used for evaluation of textile cytotoxicity (DIN EN ISO 10993-12). In brief, $1 \mathrm{~g}$ was incubated in $50 \mathrm{~mL}$ of Dulbecco's modified Eagle's medium (DMEM) in Erlenmeyer flasks (Greiner, Frickenhausen, Germany) at $37^{\circ} \mathrm{C}$ for 24 hours under shaking

Table I Summary of the results of the in vivo pilot study

\begin{tabular}{lll}
\hline & Before trial & After trial \\
\hline Pruritus severity & $3.5 \pm \mathrm{I} .2$ & $2.4 \pm \mathrm{I} . \mathrm{I}$ \\
Erythema & $2.2 \pm 0.8$ & $\mathrm{I} .0 \pm 0.8$ \\
Edema and papules & $\mathrm{I} .9 \pm 0.8$ & $0.8 \pm 0.6$ \\
Excoriations & $\mathrm{I} .7 \pm \mathrm{I} . \mathrm{I}$ & $0.6 \pm 0.5$ \\
Impairment by pruritus & $3.7 \pm 0.7$ & $2 . \mathrm{I} \pm \mathrm{I} . \mathrm{I}$ \\
Impairment of night sleep & $\mathrm{I} .7 \pm \mathrm{I} .4$ & $\mathrm{I} .4 \pm 0.7$ \\
Impairment at work & $\mathrm{I} .4 \pm \mathrm{I} .5$ & $0.7 \pm \mathrm{I} .2$ \\
Impairment at leisure time & $\mathrm{I} .4 \pm \mathrm{I} .6$ & $0.7 \pm \mathrm{I} .2$ \\
Impairment at housework & $\mathrm{I} .4 \pm \mathrm{I} .5$ & $\mathrm{I} .0 \pm \mathrm{I} .3$ \\
\hline
\end{tabular}

A

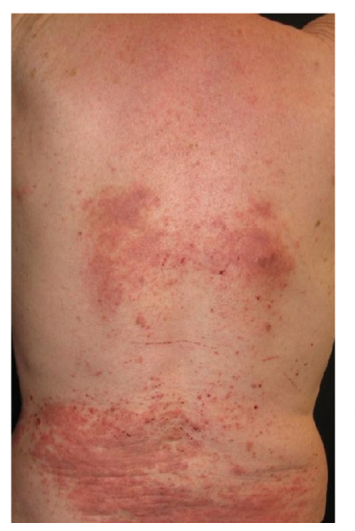

B

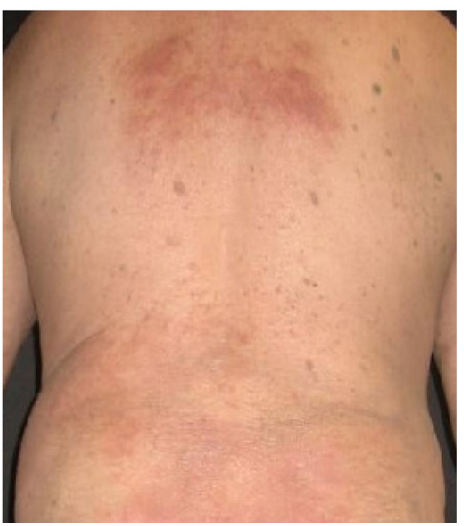

Figure 2 Clinical improvement of nummular atopic dermatitis with adjuvant $\mathrm{ZnO}$ textile overnight $(\mathbf{A})$ before and $(\mathbf{B})$ after 4 days.

(ThermoBath, GFL, Großburgwedel, Germany). At all times, samples were handled under sterile conditions and extra care was taken for avoiding cross-contamination. Subsequently, extracts were centrifuged at $1000 \mathrm{rpm}$ over gauze to dispose of insoluble material residues. The resulting filtrate was sterilized afterwards by passage through a $0.2 \mu \mathrm{m}$ filter and classified as original extract (100\%).

Human $\mathrm{HaCaT}$ keratinocytes were a kind gift from NE Fusenig of the German Cancer Research Center, Heidelberg, Germany. The cells are routinely cultured in DMEM supplemented with $1 \%$ antibiotic-antimycotic solution $(10,000 \mathrm{U} / \mathrm{mL}$ penicillin, $10,000 \mu \mathrm{g} / \mathrm{mL}$ streptomycin, $25 \mu \mathrm{g} / \mathrm{mL}$ amphotericin; PromoCell, Heidelberg, Germany) and $10 \%$ fetal calf serum (PromoCell) for 7 days in $75 \mathrm{~cm}^{2}$ cell-culture flasks (Greiner) at $37^{\circ} \mathrm{C}$ in a humidified atmosphere containing 5\% $\mathrm{CO}_{2}$. For biocompatibility experiments, cells were harvested by trypsin-ethylenediaminetetraacetic acid (PromoCell) treatment, seeded into 96-well plates (Greiner) at a density of 40,000 cells $/ \mathrm{cm}^{2}$, and left for 48 hours. Then, culture medium was swapped for either fresh medium (negative control) or Zn-textile extracts in medium (original extract 100\%,

A

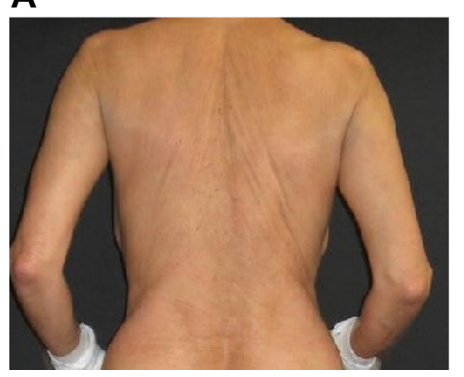

Figure 3 Clinical improvement of disseminated atopic dermatitis with adjuvant $\mathrm{ZnO}$ textile overnight $(\mathbf{A})$ before and $(\mathbf{B})$ after 4 days.
B

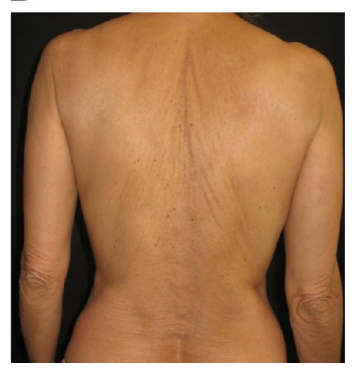




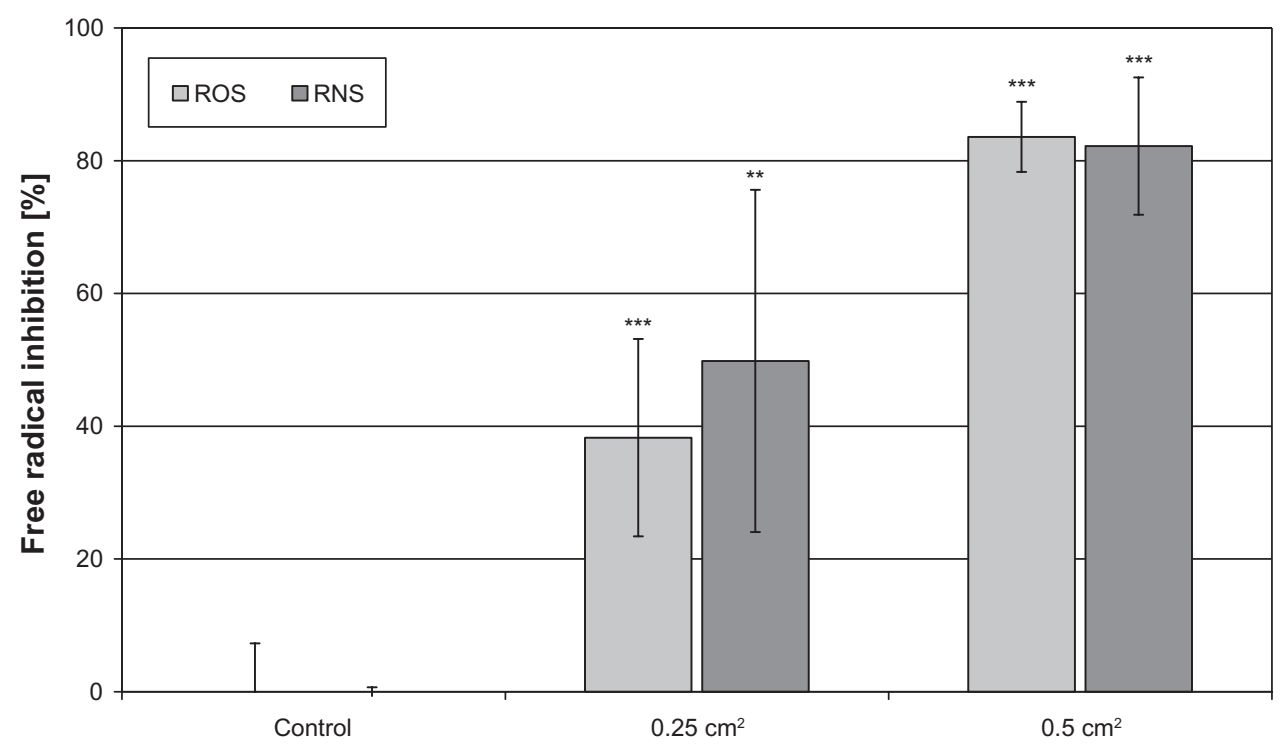

Figure $4 \mathrm{~A}$ high antioxidative capacity was determined for the ZnO-textile.

Notes: It was equally effective in inhibiting reactive oxygen species (ROS) and reactive nitrogen species (RNS) formation in vitro. **P $\leqslant 00.0 \mathrm{I} ; * * P \leqslant 0.00 \mathrm{I}$.

extraction ratio $1 \mathrm{~g}: 50 \mathrm{~mL}$ ) and serial dilutions of the original extract $(75 \%$ at $0.75 \mathrm{~g}: 50 \mathrm{~mL}, 50 \%$ at $0.5 \mathrm{~g}: 50 \mathrm{~mL}, 25 \%$ at $0.25 \mathrm{~g}: 50 \mathrm{~mL}$, and $10 \%$ at $0.1 \mathrm{~g}: 50 \mathrm{~mL}$ ). As positive control for cytotoxicity, a Triton-X 100 (Merck, Darmstadt, Germany) was utilized. The HaCaT cells were afterwards incubated for 1,24 , and 48 hours followed by determination of cell viability and proliferation, which was performed on the basis of a luminometric adenosine triphosphate (ATP) assay (ATPLite M Assay; PerkinElmer, Waltham, MA, USA), as reported previously. ${ }^{22}$ Briefly, lysis solution was added to each well, followed by the substrate solution (luciferase/D-luciferin). After incubation, luminescence was determined using the Lumistar Galaxy microplate luminometer (BMG Labtech). Cellular ATP content was calculated on the basis of a standard curve. For illustration, the number of viable cells was expressed as a percentage of the control cells at the respective time point. Cytotoxic effects were analyzed by measurement of lactate dehydrogenase release using a cytotoxicity detection kit (Roche, Basel, Switzerland). The assay was run according to the manufacturer's instructions. Optical density was determined at $490 \mathrm{~nm}$ with a reference measurement at $620 \mathrm{~nm}$ (Fluostar; BMG Labtech). Afterwards, cytotoxicity was evaluated by

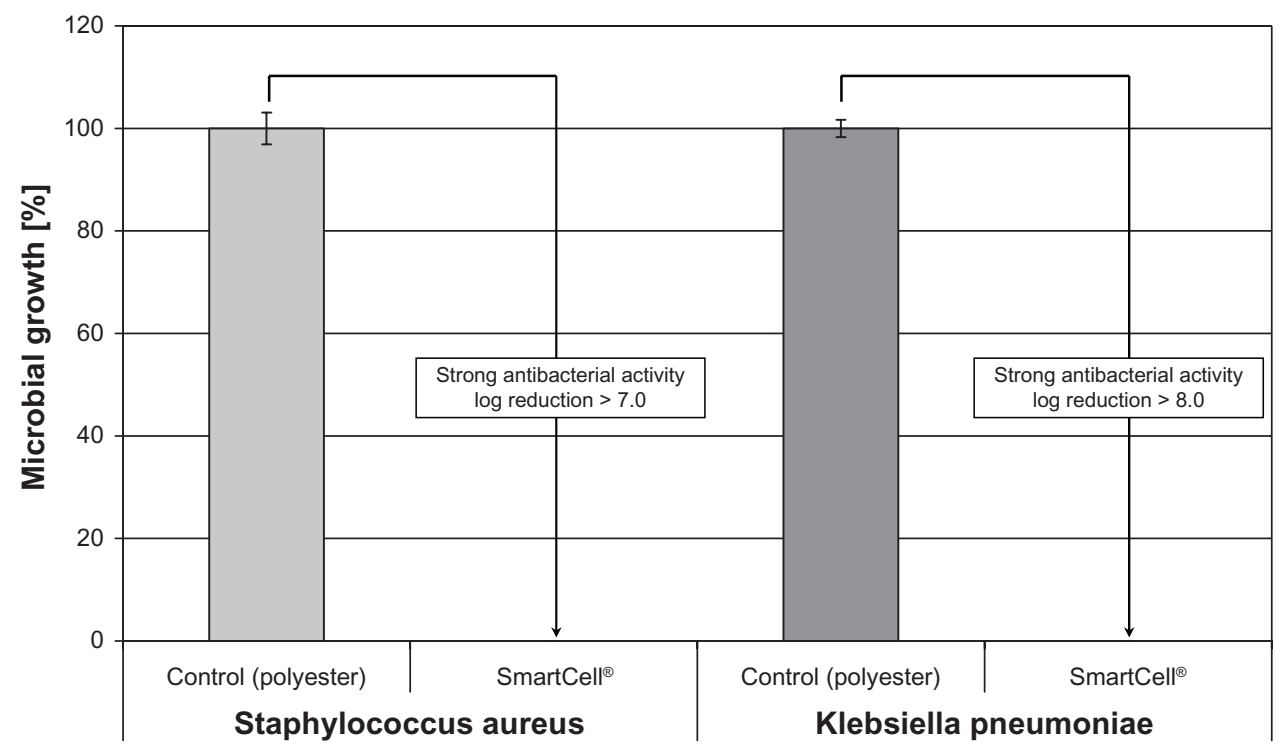

Figure 5 The $\mathrm{ZnO}$ textile possesses a strong antibacterial effect (log reduction $>3$ ) against both Staphylococcus aureus and Klebsiella pneumoniae. Note: Complete inhibition of microbial growth was achieved. 
calculation of the percentage of the optical density of treated cells compared to control cells.

\section{Results}

\section{In vivo results}

The results of the in vivo pilot trial are summarized in Table 1. Twelve adult AD patients were included (five women, seven men) with a mean age of $60.6 \pm 15.1$ years (range 28-78 years). Before the use of the $\mathrm{Zn}$ textile, the average pruritus duration was 6-24 hours a day. Only four patients reported less than 6 hours of pruritus. After three nights with the $\mathrm{Zn}$ textile, ten patients reported less than 6 hours of pruritus. None of the patients suffered from pruritus all day long. Pruritus severity dropped from

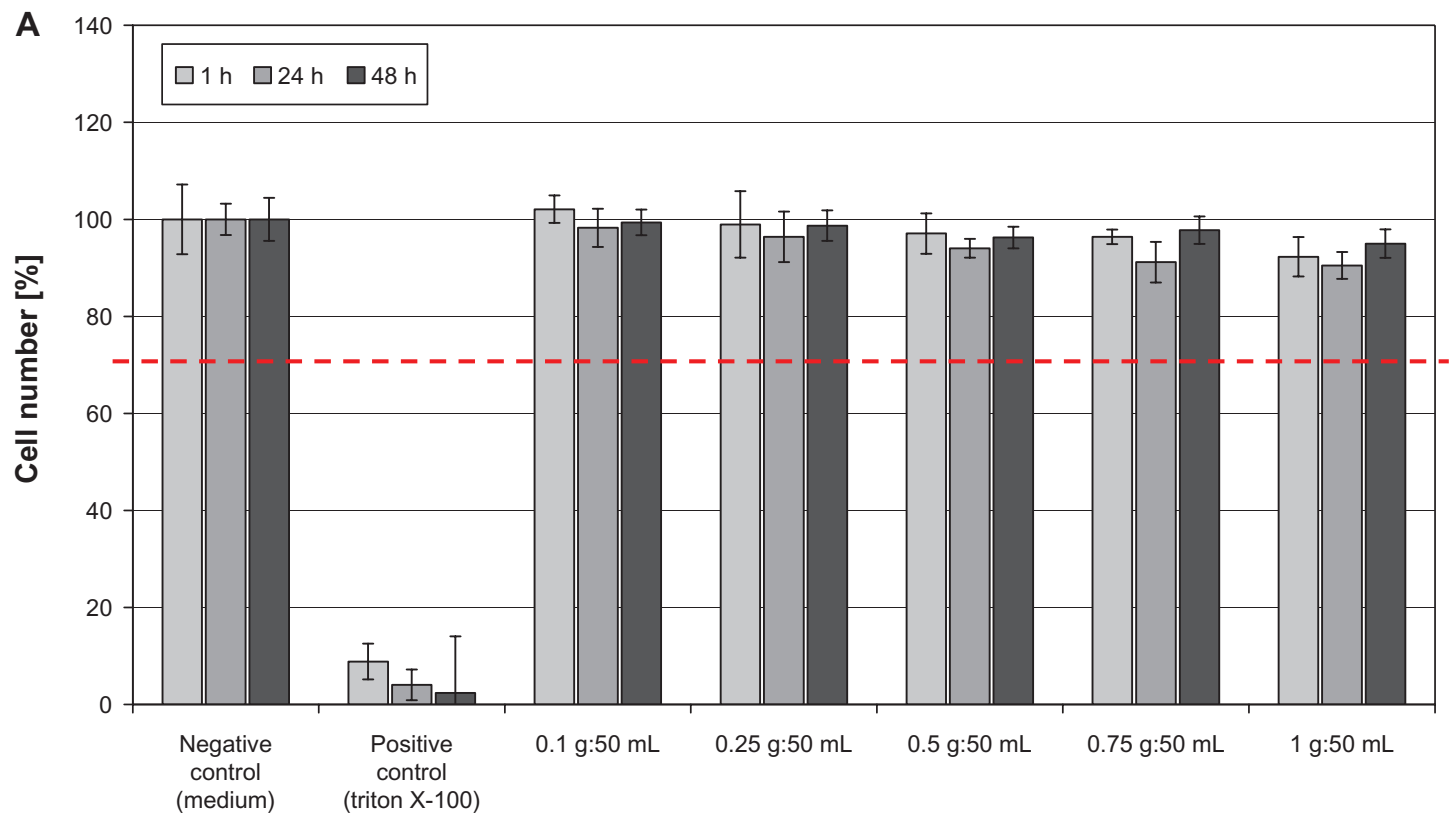

Extraction ratio

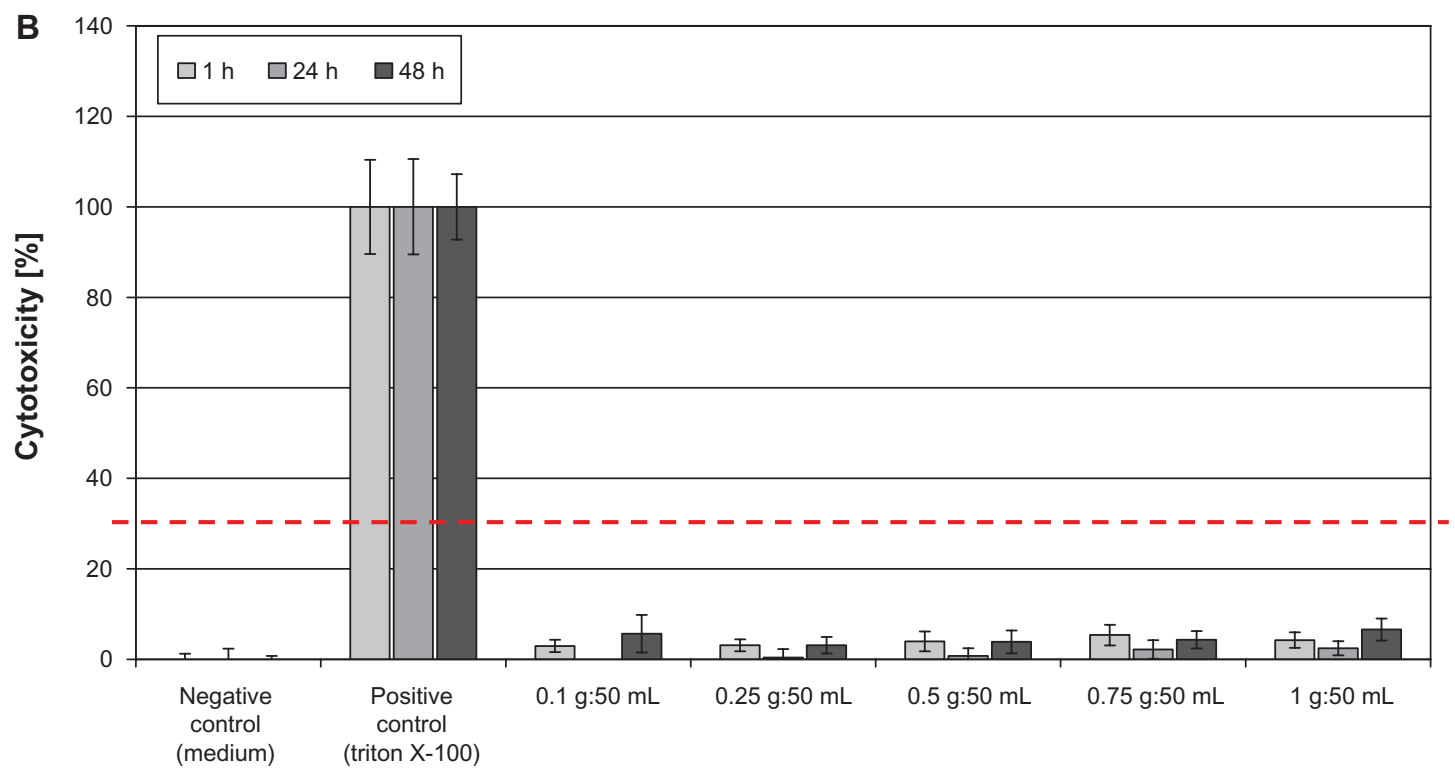

\section{Extraction ratio}

Figure 6 (A) Determination of $\mathrm{HaCaT}$ keratinocyte cell viability and cell proliferation after I, 24, and 48 hours of incubation with ZnO-textile extract. No negative effect on the cells was observed in vitro. At no time point or extraction ratio tested did cell numbers drop below the $70 \%$ threshold (red dotted line). (B) A significant release of lactate dehydrogenase was observed only for the positive control Triton X-100.

Notes: None of the $\mathrm{ZnO}$ textile-extraction ratios tested exhibited a cytotoxic potential. In accordance, cytotoxicity did not reach the threshold of $30 \%$ (red dotted line). 
$3.5 \pm 1.2$ to $2.4 \pm 1.1$. Impairment by pruritus was scored $3.7 \pm 0.7$ and decreased to $2.1 \pm 1.1$.

The impairment of night sleep improved from $1.7 \pm 1.4$ to $1.4 \pm 0.7$. Impairment during professional activities improved from $1.4 \pm 1.5$ to $0.7 \pm 1.2$. Impairment of leisure time was reduced from $1.4 \pm 1.6$ to $0.7 \pm 1.2$. Housework impairment also decreased from $1.4 \pm 1.5$ to $1.0 \pm 1.3$.

Overall, sleep quality seemed to be better after use of the $\mathrm{Zn}$ textile. The number of patients suffering from wakefulness was reduced from five to two. Problems falling asleep were reported by six patients before use of the $\mathrm{Zn}$ textile and reduced to four patients after the use of the $\mathrm{Zn}$ textile overnight. Wake-up periods were noted by nine patients before and only six patients after the test period. Sleeping duration remained unchanged.

In addition, clinical cutaneous symptoms improved distinctly. Erythema decreased from $2.2 \pm 0.8$ to $1.0 \pm 0.8$, edema and papules decreased from $1.9 \pm 0.8$ to $0.8 \pm 0.6$, and excoriations reduced from $1.7 \pm 1.1$ to $0.6 \pm 0.5$ (Figures 2 and 3).

\section{In vitro effects}

The Zn textile exhibited a significant antioxidant capacity against ROS as well as RNS in vitro (Figure 4). As illustrated, it exerted a dose-dependent effect. Moreover, it was shown that it is equally effective against ROS and RNS.

In addition, strong antibacterial activity against both Staphylococcus aureus and Klebsiella pneumoniae was observed, yielding log reductions $>3$ (Figure 5). Bacterial growth was completely inhibited after a 24-hour incubation period.

Figure 6 shows the results of the biocompatibility study performed according to DIN EN ISO 10993-5, used for evaluation of cytotoxic effects of textiles. Treatment of human $\mathrm{HaCaT}$ keratinocytes with $\mathrm{Zn}$-textile extract had no negative influence on cell viability or cell proliferation (Figure 6A). In accordance, no cytotoxic potential, inducing cell death by necrosis, was observed (Figure 6B).

\section{Discussion}

$\mathrm{AD}$ is a chronic inflammatory disease characterized by the impairment of the skin-barrier function, increased oxidative cellular stress, and bacterial colonization. The development of new textiles with intrinsic properties such as antioxidative capacity and antibacterial activity presents a promising path in the treatment and maintenance of AD. Here, we observed a rapid improvement of $\mathrm{AD}$ severity, pruritus, and subjective sleep quality when $\mathrm{AD}$ patients wore the Benevit Zink+ clothing overnight. This textile comprises a specially coated $\mathrm{ZnO}$ fiber with high AOC against ROS and RNS, as well as strong antibacterial activity. In general, natural fibers like silk or cotton are preferred for individuals with sensitive skin or $\mathrm{AD} .{ }^{23}$ These fibers can be functionalized by incorporation of silver or chitosan to reduce colonization of AD skin by staphylococci for improvement of disease severity. ${ }^{24-26}$ However, negative effects on cells of both silver ions $^{21,27}$ and chitosan formulations ${ }^{22,28,29}$ have been observed in vitro. Moreover, the use of silver compounds has been associated with the risk of inducing bacterial adaptation. ${ }^{30-32}$ Hence, there is a demand for alternative effective compounds. $\mathrm{ZnO}$ may present an interesting option, as it provides sun protection $^{33}$ and has been shown to improve hypertrophic scars. ${ }^{34} \mathrm{ZnO}$ helps to restore the disturbed skin-barrier function in eczematous diseases ${ }^{35}$ and enhances wound healing. ${ }^{36}$ Moreover, $\mathrm{ZnO}$ is considered safe to use, since it does not penetrate the skin, even with disturbed barrier function..$^{37,38}$ In accordance, high biocompatibility of the Benevit Zink+ was proven in this study in vitro. In addition, we were able to demonstrate that short time usage of this $\mathrm{ZnO}$ textile can contribute to improvement of night sleep, pruritus, and $\mathrm{AD}$ severity when used adjuvant to medical treatment. Hereby, an improvement of quality of life can be achieved for $\mathrm{AD}$ patients.

\section{Acknowledgments}

The authors would like to thank Dr Michael Zieger, Doreen Winter, Peggy Gasch, and Martina Grebner for excellent technical assistance.

\section{Disclosure}

The study was supported by an unrestricted grant of Benevit Van Clewe, Dingden, Germany. The authors report no other conflicts of interest in this work.

\section{References}

1. Kubo M, Kambayashi Y, Takemoto K, Okuda J, Muto M, Ogino K. Reactive nitrogen species formation in eosinophils and imbalance in nitric oxide metabolism are involved in atopic dermatitis-like skin lesions in NC/Nga mice. Free Radic Res. 2005;39(7):719-727.

2. Korkina L, Pastore S. The role of redox regulation in the normal physiology and inflammatory diseases of skin. Front Biosci (Elite Ed). 2009; 1:123-141.

3. Chung J, Oh SY, Shin YK. Association of glutathione-S-transferase polymorphisms with atopic dermatitis risk in preschool age children. Clin Chem Lab Med. 2009;47(12):1475-1481.

4. Sapuntsova SG, Lebed'ko OA, Shchetkina MV, Fleyshman MY, Kozulin EA, Timoshin SS. Status of free-radical oxidation and proliferation processes in patients with atopic dermatitis and lichen planus. Bull Exp Biol Med. 2011;150(6):690-692. 
5. Addor FA, Takaoka R, Rivitti EA, Aoki V. Atopic dermatitis: correlation between non-damaged skin barrier function and disease activity. Int $J$ Dermatol. 2012;51(6):672-676.

6. Melnik B. Disturbances of antimicrobial lipids in atopic dermatitis. J Dtsch Dermatol Ges. 2006;2(2):114-123. German.

7. Baker BS. The role of microorgamisms in atopic dermatitis. Clin Exp Dermatol. 2006;144(1):1-9.

8. Leyden JJ, Marples RR, Kligman AM. Staphylococcus aureus in the lesions of atopic dermatitis. Br J Dermatol. 1974;90(5):525-530.

9. Aly R, Maibach HI, Shinefield HR. Microbial flora of atopic dermatitis. Arch Dermatol. 1977;113(6):780-782.

10. Roll A, Cozzio A, Fischer B, Schmid-Grendelmeier P. Microbial colonization and atopic dermatitis. Curr Opin Allergy Clin Immunol. 2004;4(5):373-378.

11. Stinco G, Piccirillo F, Valent F. A randomized double-blind study to investigate the clinical efficacy of adding a non-migrating antimicrobial to a special silk fabric in the treatment of atopic dermatitis. Dermatol. 2008;217(3):191-195.

12. Ring J, Alomar A, Bieber T, et al. Guidelines for treatment of atopic eczema (atopic dermatitis) part I. J Eur Acad Dermatol Venereol. 2012;26(8):1045-1060.

13. Ring J, Alomar A, Bieber T, et al. Guidelines for treatment of atopic eczema (atopic dermatitis) part II. J Eur Acad Dermatol Venereol. 2012;26(9):1176-1193.

14. Valdman-Grinshpoun Y, Ben-Amitai D, Zvulunov A. Barrierrestoring therapies in atopic dermatitis: current approaches and future perspectives. Dermatol Res Pract. 2012;2012:923134.

15. Wollina U, Abdel-Naser MB, Verma S. Skin physiology and textiles - consideration of basic interactions. Curr Probl Dermatol. 2006;33:1-16.

16. Hanifin J, Rajka G. Diagnostic features of atopic dermatitis. Acta Derm Venereol. (Stockh). 1980;59 Suppl 92:44-47.

17. Wolkerstorfer A, de Waard van der Spek FB, Glazenburg EJ, Mulder PG, Oranje AP. Scoring the severity of atopic dermatitis: three item severity score as a rough system for daily practice and as a pre-screening tool for studies. Acta Derm Venereol (Stockh). 1999;79(5):356-359.

18. Elman S, Hynan LS, Gabriel V, Mayo MJ. The 5-D itch scale: a new measurement of pruritus. Br J Dermatol. 2010;162(3):587-593.

19. Unruh ML, Sanders MH, Redline S, et al. Subjective and objective sleep quality in patients on conventional thrice-weekly hemodialysis: comparison with matched controls from the sleep heart health study. Am J Kidney Dis. 2008;52(2):305-313.

20. Schönfelder U, Abel M, Wiegand C, Klemm D, Elsner P, Hipler UC Influence of selected wound dressings on PMN elastase in chronic wound fluid and their antioxidative potential in vitro. Biomaterials. 2005;26(33):6664-6673.

21. Wiegand C, Heinze T, Hipler UC. Comparative in vitro study on cytotoxicity, antimicrobial activity, and binding capacity for pathophysiological factors in chronic wounds of alginate and silver-containing alginate. Wound Repair Regen. 2009;17(5):511-521.

22. Wiegand C, Winter D, Hipler UC. Molecular-weight-dependent toxic effects of chitosans on the human keratinocyte cell line HaCaT. Skin Pharmacol Physiol. 2010;23(3):164-170.
23. Ricci G, Neri I, Ricci L, Patrizi A. Silk fabrics in the management of atopic dermatitis. Skin Therapy Lett. 2012;17(3):5-7.

24. Fluhr JW, Breternitz M, Kowatzki D, et al. Silver-loaded seaweed-based cellulosic fiber improves epidermal skin physiology in atopic dermatitis: safety assessment, mode of action and controlled, randomized singleblinded exploratory in vivo study. Exp Dermatol. 2010;19(8):e9-e15.

25. Park KY, Jang WS, Yang GW, et al. A pilot study of silver-loaded cellulose fabric with incorporated seaweed for the treatment of atopic dermatitis. Clin Exp Dermatol. 2012;37(5):512-515.

26. Tavaria FK, Soares JC, Reis IL, Paulo MH, Malcata FX, Pintado ME. Chitosan: antimicrobial action upon staphylococci after impregnation onto cotton fabric. J Appl Microbiol. 2012;112(5):1034-1041.

27. Hidalgo E, Bartolomé R, Barroso C, Moreno A, Domínguez C. Silver nitrate: antimicrobial activity related to cytotoxicity in cultured human fibroblasts. Skin Pharmacol Appl Skin Physiol. 1998;11(3):140-151.

28. Chatelet C, Damour O, Domard A. Influence of the degree of acetylation on some biological properties of chitosan films. Biomaterials. 2001; 22(3):261-268.

29. Freier T, Koh HS, Kazazian K, Shoichet MS. Controlling cell adhesion and degradation of chitosan films by N-acetylation. Biomaterials. 2005; 26(29):5872-5878.

30. Silver S. Bacterial silver resistance: molecular biology and uses and misuses of silver compounds. FEMS Microbiol Rev. 2003 27(2-3):341-353.

31. Warriner R, Burrell R. Infection and the chronic wound: a focus on silver. Adv Skin Wound Care. 2005;18 Suppl 1:2-12.

32. Wiegand C, Abel M, Ruth P, Hipler UC. Analysis of the adaptation capacity of Staphylococcus aureus to commonly used antiseptics by microplate laser nephelometry. Skin Pharmacol Physiol. 2012 25(6):288-297.

33. Shimizu I, MacFarlane D. Zinc oxide paste as sunscreen in the postoperative period. Dermatol Surg. 2012;38(6):965-966.

34. Aksoy B, Atakan N, Aksoy HM, et al. Effectiveness of topical zinc oxide application on hypertrophic scar development in rabbits. Burns 2010;36(7):1027-1035

35. Xhauflaire-Uhoda E, Henry F, Piérard-Franchimont C, Piérard GE. Electrometric assessment of the effect of a zinc oxide paste in diaper dermatitis. Int J Cosmet Sci. 2009;31(5):369-374.

36. Lansdown AB, Mirastschijski U, Stubbs N, Scanlon E, Agren MS. Zinc in wound healing: theoretical, experimental, and clinical aspects. Wound Repair Regen. 2007;15(1):2-16.

37. Zvyagin AV, Zhao X, Gierden A, Sanchez W, Ross JA, Roberts MS Imaging of zinc oxide nanoparticle penetration in human skin in vitro and in vivo. J Biomed Opt. 2008;13(6):064031.

38. Lin LL, Grice JE, Butler MK, et al. Time-correlated single photon counting for simultaneous monitoring of zinc oxide nanoparticles and $\mathrm{NAD}(\mathrm{P}) \mathrm{H}$ in intact and barrier-disrupted volunteer skin. Pharm Res. 2011;28(11):2920-2930.
Clinical, Cosmetic and Investigational Dermatology

\section{Publish your work in this journal}

Clinical, Cosmetic and Investigational Dermatology is an international, peer-reviewed, open access, online journal that focuses on the latest clinical and experimental research in all aspects of skin disease and cosmetic interventions. All areas of dermatology will be covered; contributions will be welcomed from all clinicians and

\section{Dovepress}

basic science researchers globally. This journal is indexed on CAS The manuscript management system is completely online and includes a very quick and fair peer-review system, which is all easy to use. Visit http://www.dovepress.com/testimonials.php to read real quotes from published authors. 